\section{Outstanding Business Reference Sources 2019}

\section{BRASS Business Information Sources Committee}

\author{
BRASS Business Information Sources Committee \\ contributing members: Ben Hall; Holly Inglis, \\ nominations coordinator; Wendy Girven Pothier, \\ selections editor; Lauren Reiter; and Kendra Spahr. \\ Correspondence concerning this column should be \\ addressed to Wendy Girven Pothier, Business Librarian, \\ Dimond Library, University of New Hampshire, Durham, \\ New Hampshire, USA; email: wendy.pothier@unh.edu
}

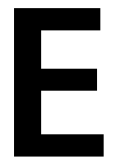
ach year, the Business Information Sources Committee of BRASS selects the outstanding business reference sources published since May of the previous year. This year, the committee reviewed fourteen entries; of these, one was designated as "Outstanding" and four as "Notable." To qualify for the award, the title must meet the conventional definition of reference: a work compiled specifically to supply information on a certain subject or group of subjects in a form that will facilitate its ease of use. The works are examined for the following: authority and reputation of the publisher, author, or editor; accuracy; appropriate bibliography; organization; comprehensiveness; value of the content; currency; distinctive addition; ease of use for the intended purpose; quality and accuracy of index; and quality and usefulness of graphics and illustrations. Additional criteria for electronic reference titles are accuracy of links, search features, stability of content, and graphic design. Works selected must be suitable for medium to large-size academic and public libraries.

\section{OUTSTANDING}

Economic Indicators for Professionals: Putting Statistics into Perspective. Charles Steindel. New York: Routledge, 2018. 222 p. Hardcover $\$ 150$ (ISBN: 9781138559240 ). Contact publisher for e-book pricing (ISBN: 9780203712955$).$

Economic Indicators for Professionals: Putting Statistics into Perspective is a reference source that defines and delves into the important economic indicators used by the public, policymakers, economists, analysts, financial markets, and media. Drawing from years of experience as an economist, the author, Charles Steindel, describes different US economic numbers issued by the Bureau of Economic Analysis, Bureau of Labor Statistics, Census Bureau, and other agencies and organizations. Steindel expands beyond detailed explanations of the indicators to discuss how they fit into the larger picture. With this approach, the author has developed a reference book for professionals in business, policy, media, and other sectors; students; investors; and other individuals that would like to gain a better understanding of the US economy through data.

The volume's content is divided into sixteen chapters, each covering specific economic indicators, as well as an introduction and conclusion. The first chapter, which addresses GDP (gross domestic product), is the longest and most in-depth of all chapters. It addresses what GDP measures, why it is used, and how the data are produced. While 


\section{FROM COMMITTEES OF RUSA}

this chapter does mention formulas used in the computation of aggregate GDP, the book does not focus on technical descriptions, and they are limited throughout the rest of the text. The following several chapters are shorter in length and expand the discussion of GDP by breaking down its components, including consumer spending, inventory investment, imports and exports, and government spending. In these chapters, Steindel explains the data used to construct estimates, suggest a path, and model that indicator, as well as any caveats. For example, he explains that while there is a lack of reliable data to indicate the path of consumer spending, there is an abundance of data that can be used for modeling, such as household income and personal savings rate. Additional indicators discussed in subsequent chapters include income and wealth, pricing, labor market, and state and regional data, rounding out a broad survey of important economic numbers.

The appendix of Economic Indicators for Professionals: Putting Statistics into Perspective features an overview of the major US datasets discussed in each chapter. This handy tool covers the dataset, issuer, shortest period references, and frequency of release. Other key features of the book include a high-quality index and significant notes and references at the end of each chapter.

What makes Economic Indicators for Professionals: Putting Statistics into Perspective outstanding is that it provides not only explanations of various US economic data but also the context that helps a reader better understand the data and the overall economy. While it is not overly technical, it would be most useful for patrons with some working knowledge of economics concepts. Overall, Economic Indicators for Professionals: Putting Statistics into Perspective is a practical, wellorganized, and engaging reference source that would be a suitable addition to an academic, public, or special library collection._L Lauren Reiter, Penn State University

\section{NOTABLE}

The Cambridge Handbook of the Law of the Sharing Economy. Edited by Nestor M. Davidson, Michèle Finck, and John J. Infranca. Cambridge, UK: Cambridge University Press, 2018. 516 p. Hardcover \$225 (ISBN: 9781108416955 ). \$180 e-book (ISBN: 9781108271660).

The Cambridge Handbook of the Law of the Sharing Economy is a reference title that handles issues of the sharing economy and its impact on law, as well as how law shapes the sharing economy, a phenomenon that has risen globally over the past decade. The work features scholarly contributions from authors across the globe with diverse academic backgrounds.

The Handbook of the Law of the Sharing Economy is divided into two broad parts and contains a total of seven sections. The first part provides an overview and looks at the regulatory landscape of the sharing economy. The second part addresses specific regulatory concerns within the sharing economy. Both parts cover a wide range of legal jurisdictions, with an emphasis on the United States and the European Union, and a range of companies, both big and small, involved in the sharing economy. Within the two broad parts, sections on topics include an overview and definition of the sharing economy, balancing regulation and innovation, framing the regulatory response, determining who regulates the law and how, employment and labor law, tax law, and consumer protection and privacy law. Each section contains multiple chapters.

The Handbook of the Law of the Sharing Economy is a notable reference title for its groundbreaking content regarding the fast-moving world of regulation and the sharing economy and its wide-arching view of the phenomenon regarding the law. It would be appropriate for addition to an academic, public, or special library collection and will appeal to an audience of students and scholar from business, law, and interdisciplinary backgrounds.-Wendy Girven Pothier, University of New Hampshire

Handbook of Research Methods in Diversity Management, Equality and Inclusion at Work. Edited by Lize A. E. Booysen, Regine Bendl, and Judith K. Pringle. Cheltham, UK: Edward Elgar Publishing, 2018. 542 p. Hardcover \$260 (ISBN: 9781783476077). Contact publisher for e-book pricing (ISBN: 9781783476084).

The Handbook of Research Methods in Diversity Management, Equality and Inclusion at Work focusses on the philosophical foundations, social and historical contexts, and set of practices associated with select research methodologies for equality, diversity, and inclusion (EDI) in management and organizations. In the introduction, the editors state that the book is intended to address the epistemological challenges of EDI research, offering new "methodological perspectives and analytic directions to advance empirical EDI research."

The edited volume contains twenty-two chapters, organized into three parts: "Research Dilemmas in EDI," "Methodology and Methods for Collecting EDI Material," and "Methods and Techniques for EDI Data Analysis." Chapters cover topics such as participatory action research, metaanalysis, autoethnography, grounded theory, and indigenous research. Each chapter provides an overview and discussion of a topic, specific examples of relevant empirical research, potential directions for future research, and a reference list. One of the strengths of the Handbook is that chapters integrate epistemological foundations and researcher positions with discussions about the advantages and weaknesses of applying different methods, methodologies, or types of analysis in the context of EDI research. For example, the chapter "Queering Quantitative Research" discusses queer theory as framework for analyzing normative categories, describes heteronormative assumptions in official statistical sources, and gives examples of the ways that organizations are designing surveys to collect more sophisticated and inclusive data.

Though the Handbook is oriented toward researchers in management and organizational studies, its contents could be informative for graduate students and faculty in a range 
of disciplines. This volume would be an excellent addition for most medium- to large-size academic libraries, especially those at institutions with entrepreneurship, organizational studies, management, human resources, or leadership programs.-Kendra Spahr, Kansas State University

The Oxford Handbook of Meaningful Work. Edited by Ruth Yeoman, Catherine Bailey, Adrian Madden, and Marc Thompson. Oxford, UK: Oxford University Press, 2019. 544 p. Hardcover \$125 (ISBN: 9780198788232).

The Oxford Handbook of Meaningful Work provides an interdisciplinary examination of meaningful work in various contexts. Although it is primarily for the academic market, due to the limited material in this area, the scope of coverage may appeal to large public libraries as well in order to fill a collection gap or provide contemporary perspectives.

There are four sections and twenty-seven chapters within. The first two parts will largely be of interest to academic researchers and parts 3 and 4 have academic and broader appeal. Part 1 covers the Philosophy of Meaningful Work; part 2, the Processes of Meaningfulness; part 3, the Experience of Meaningful Work, and part 4 is about Contexts and Boundaries of Meaningful Work. The authors are primarily interdisciplinary scholars from academic institutions in the United States and the United Kingdom. A few of the authors are from various professions, including an organizational consultant and a nurse.

Coverage includes corporate social responsibility, globalization, family life, technological change, and a chapter on the meaningful city which includes civic work. The chapter on the third sector (voluntary or non-profit sector) includes social service, political activism, humanitarianism, and development. Chapter 17, "Does My Engagement Matter? Exploring the Relationship Between Employee Engagement and Meaningful Work in Theory and Practice," provides a succinct overview of the literature and practical examples for employers to use to engage employees instead of practices that repeatedly show poor results.

For electronic access, the index is problematic via the Oxford handbook platform in that it does not indent for subcategories, leaving it to appear as an out of alphabetical order list. It is properly indented in the print version. The electronic index does link directly to related material, saving users' time.-Holly Inglis, University of Toronto
The Palgrave Handbook of Wine Industry Economics. Edited by Adeline Alonso Ugaglia, Jean-Marie Cardebat, and Alessandro Corsi. Palgrave Macmillan, 2019. 542 p. Hardcover \$169 (ISBN: 978-3319986326). Contact publisher for e-book pricing (ISBN: 9783319986333).

As with each of the Palgrave Handbooks, The Palgrave Handbook of Wine Industry Economics provides insights to key development questions. It also offers perhaps the most authoritative international economic comparison of wine industry sectors, regulations, and global business models.

Since globalization has changed the make-up of the international wine market over the last fifteen years, the editors ponder whether "different countries will follow a general convergence trend or if different models can and will coexist [in the wine industry] in the next years." What follows is a noteworthy outline which attempts to answer several specific questions: What are the favorable models of industrial organization in top wine-producing countries? And, what could the world of wine look like by 2030 ?

The Handbook is divided into five main parts. Part 1 - the bulk of the handbook-identifies the wine industry supply chain and models of production relative to ten wine sectors worldwide. Adding structure, this part also contextualizes regional markets; for example, "In the Australian domestic market (where $35-40 \%$ of production is sold) . . just two supermarket chains (Coles and Woolworths) account for the majority of domestic wine sales." Part 2 focuses on the influence of trade policies alongside the role of international organizations, such as the International Organization of Vine and Wine (OIV) and the World Wide Trade Group (WWTG). Finally, the concluding parts 3 through 5 provide case studies of relevant wine industry models (e.g., old and new wine worlds) and strategies (e.g., vertical integration), each governed according to national and international micro- and macroeconomic trends.

The Palgrave Handbook of Wine Industry Economics received contributions from economists in Europe, South and North America, Australia, South Africa and China. Although the strategy chapters would be most valuable for wine industry business professionals, the Handbook's depth of historical context and commentary on regional trends provide an excellent foundation for anyone who enjoys learning more about wine. This work is a noteworthy resource for inclusion in an academic library or agricultural resource collection. —Benjamin Hall, Michigan State University 